TP Periodica Polytechnica Chemical Engineering

\author{
62(3), pp. 351-358, 2018 \\ https://doi.org/10.3311/PPch.10686 \\ Creative Commons Attribution (i)
}

RESEARCH ARTICLE

\section{Red Arecanut Seed Extract as a Sustainable Corrosion Inhibitor for Aluminum Submerged in Acidic Corrodent: An Experimental Approach Towards Zero Environmental Impact}

\author{
Narasimha Raghavendra ${ }^{1}$, Jathi Ishwara Bhat ${ }^{1 *}$
}

Received 02 March 2017; accepted after revision 10 July 2017

\begin{abstract}
The effect of the red arecanut seed (RAS) extract on the corrosion of aluminum in $0.5 \mathrm{M}$ hydrochloric acid environment is reported by weight loss, electrochemical (Tafel plot and impedance spectroscopy), scanning electron microscopy and atomic force microscopy studies. The weight loss study indicated that, protection efficiency of the red arecanut seed extract is directly proportional to its concentration and inversely proportional to solution temperature and aluminum contact time in the test solution. Langmuir adsorption isotherm is best fitted model explaining the adsorption of red arecanut seed extract constituents on aluminum surface in $0.5 \mathrm{M} \mathrm{HCl}$ system. The results obtained from Tafel curves indicated the mixed inhibition role of red arecanut seed extract. The impedance spectroscopy technique indicated that, red arecanut seed extract reduces the speed of aluminum corrosion by charge transfer process. The scanning electron microscopy and atomic force microscopy images of aluminum specimens clearly give clues about the adsorption of plant constituents on the surface of the aluminum metal.
\end{abstract}

\section{Keywords}

weight loss, temperature, protection efficiency, contact time, charge transfer process

\footnotetext{
${ }^{1}$ Department of Chemistry, Mangalore University,

Mangalagangotri, Karnataka 574199, India

*Corresponding author, e-mail: bhatij@yahoo.com
}

\section{Introduction}

Prevention of aluminum corrosion in hydrochloric acid solution is very much essential due to its economic considerations, unique characteristics and prevalent applications in industrial units. When an $\mathrm{HCl}$ solution is in contact with aluminum metal, $\mathrm{HCl}$ solutions destroys the natural protective layer formed on the metal surface. Hence, free metal surface is directly exposed to corrosive solutions and undergoes dissolution. Among the numerous techniques used to prevent metal (including Al) degradation, the use of inhibitors is the best practical and low cost method and which is greatly acceptable in several industrial sections. Inhibitors are the chemical substances contains electron rich elements in their constituents, these species adsorb on metal surface and form a protective film which is responsible for the metal corrosion inhibition process [1-6].

Previously, many organic compounds have been reported as potential corrosion inhibitors for various metals in different environments. These organic compound blocks the metal corrosion process by adsorption mode [7-11]. Even though these compounds show the robust anticorrosive property, the majority of these species are expensive and unsafe to living creatures. Hence, the use of organic compounds which possessing toxic and high cost nature as corrosion inhibitors has been banned in industrial units [12-14]. Due to these reasons; scientific community focuses on inexpensive and non toxic corrosion inhibitors. Hence, the focus is shifted towards natural products (plant extracts) because of their cheap, biodegradable and eco-friendly characteristics [15, 16].

Several scientists studied the plant products such as root, seed, husk, stem, leaves and flower extracts as effective corrosion inhibitors for numerous metals in different systems. The presence of nitrogen, phosphorous, oxygen and sulfur in plant constituents plays very important role in the corrosion control process. These plant constituents prevent the corrosion process by obstructing the electrode active sites by forming insoluble complexes (adsorbed film) on the surface of the electrode. Red arecanut seed extract possessing electron rich elements in their polyphenols (gallic acid, epicatechin, procyanidin $\mathrm{B}_{1,}$ catechin, and leucocyanidin), flavonoids (rutin), fatty acids (eicosanoic 
acid, arachidonic acid, palmitic acid, oleic acid, and myristic acid, and linoleic acid), alkaloids (guvacine, isoguvacine, arecoline, guvacoline, arecaidine, and arecolidine) and tannins (tannic acid) groups [17-22]. There is no report on red arecanut seed extract as a corrosion inhibitor for any metal in any system. Therefore, in the present study, we selected red arecanut seed and studied its constituent's inhibition role.

In the present investigation, the inhibition property of the red arecanut seed extract on aluminum metal in $0.5 \mathrm{M}$ hydrochloric acid environment was tested by gravimetric (weight loss), potentiodynamic polarization (Tafel plot), AC impedance spectroscopy, scanning electron microscopy (SEM) and atomic force microscopy (AFM) techniques.

\section{Materials and Experimental Sections 2.1 Materials and test solution}

The test was performed on aluminum metal (A-63400) having the nominal chemical composition (in weight \%), Mg 0.4-0.9, Fe 0.6, Cu 0.1, Si 0.3-0.7, Mn 0.3, Zn 0.2, Tl 0.1, Cr 0.2 and remainder Al. $0.5 \mathrm{M}$ hydrochloric acid solution was prepared through standard procedure.

\subsection{Preparation of inhibitor}

The inhibitor is prepared from the red arecanut seed (see Fig. 1). Different chemical constituents from 130 grams of red arecanut seed powder was extracted by Soxhlet technique for 7 hours duration by using $470 \mathrm{ml}$ of distilled water. The different concentrations such as $2(g / L), 4(g / L), 8(g / L)$ and $12(g / L)$ was prepared and applied for corrosion studies. The presence of functional groups in the red arecanut seed extract was analyzed through Fourier transform infrared spectroscopy technique.

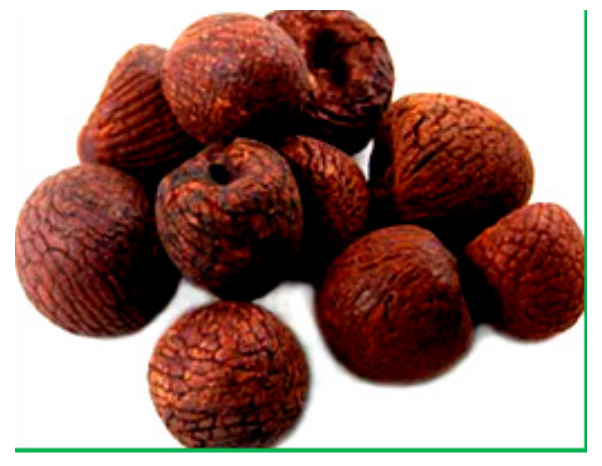

Fig. 1 Red arecanut seed used for the present investigation

\subsection{Weight loss technique}

The cleaned Al specimens were suspended in $100 \mathrm{ml}$ of $0.5 \mathrm{M} \mathrm{HCl}$ solution without and with the red arecanut seed extract of different concentrations. The test is performed at $303,308,313,318$ and $323 \mathrm{~K}$. The loss in the weight of $\mathrm{Al}$ metal was noted with respect to different immersion time intervals $(1,2,3,4,5$, and $10 h)$ by removing the corrosion products on aluminum surfaces. The test is carried out 3 times to confirm the reproducibility of the results.
The electrode (aluminum) corrosion rate in mils penetration per year (mpy) was evaluated by following mathematical relation,

$$
\text { Corrosion rate }=\frac{534 W}{A T D},
$$

where, $W=$ aluminum weight loss in $0.5 \mathrm{M} \mathrm{HCl}$ solution (milligrams), $A=$ aluminum surface area (in square inches), $T=$ exposé time of aluminum in $0.5 \mathrm{M} \mathrm{HCl}$ solution (hours), $D=$ electrode (aluminum) density (grams per cubic centimeter).

The protection efficiency of red arecanut seed extract in percentage was calculated by using below equation,

$$
\text { Protection efficiency }(\text { percentage })=\frac{\left(W_{1}-W_{2}\right)}{W_{1}} \times 100 \text {, }
$$

where, $\mathrm{W}_{1}=$ aluminum weight loss in $0.5 \mathrm{M} \mathrm{HCl}$ solution, and $\mathrm{W}_{2}=$ aluminum weight loss in $0.5 \mathrm{M} \mathrm{HCl}$ solution plus red arecanut seed extract of different concentrations.

\subsection{Electrochemical measurements}

To understand the nature of corrosion and corrosion inhibition process, the electrochemical test (CHI $660 \mathrm{C}$ ) was carried out with three electrode systems, in which aluminum metal served as working electrode; platinum electrode acts as auxiliary electrode and saturated calomel electrode worked as a reference electrode. Before taking any readings, the aluminum specimen was submerged in $0.5 \mathrm{M} \mathrm{HCl}$ solution in the absence and presence of different concentrations of red arecanut seed extract at the open circuit potential for about one hour in order to attain a steady stable state. The degree of potentiodynamic polarization curve (Tafel plots) was recorded at the applied potential range in between $+200 m v$ to $-200 m v$ with scan rate of $0.01 \mathrm{~V} / \mathrm{s}$. Nyquist plots were obtained by applying frequency in the range between the 100000 to $1 \mathrm{~Hz}$ with an amplitude of $0.01 \mathrm{~V}$.

\subsection{Surface study}

The surface morphology of the aluminum specimen immersed in $0.5 \mathrm{M} \mathrm{HCl}$ solution in the absence and presence of the red arecanut seed extract for $2 h$ duration was examined through scanning electron microscopy (SEM) and atomic force microscopy (AFM) techniques.

\section{Results and Discussion \\ 3.1 Weight loss studies}

From weight loss parameters (Tables 1 and 2), it is clear that, the protection efficiency of red arecanut seed extract gradually increases with increase its amount, while aluminum corrosion rate decreases. The increase in protection efficiency is due to increasing in the adsorption of plant extract molecules (red arecanut seed extract) on the surface of the aluminum. The adsorption of plant extract molecules on aluminum surface creates a protective film which prevents the further attack of hydrochloric acid solutions on metal surface. 
Table 1 Weight loss parameters at laboratory temperature

\begin{tabular}{|c|c|c|c|}
\hline $\begin{array}{l}\text { Time } \\
\text { (h) }\end{array}$ & $\begin{array}{l}\text { Concentration } \\
(\mathrm{g} / \mathrm{L})\end{array}$ & $\begin{array}{l}\text { Corrosion } \\
\text { rate } \times 10^{-4}(\mathrm{mpy})\end{array}$ & $\begin{array}{l}\text { Inhibition efficiency } \\
\text { in percentage }(\%)\end{array}$ \\
\hline \multirow[t]{5}{*}{1} & Blank & 8.699 & \\
\hline & 2 & 2.899 & 66.666 \\
\hline & 4 & 2.416 & 72.222 \\
\hline & 8 & 1.933 & 77.777 \\
\hline & 12 & 1.449 & 83.333 \\
\hline \multirow[t]{5}{*}{2} & Blank & 11.116 & \\
\hline & 2 & 3.866 & 65.217 \\
\hline & 4 & 3.141 & 71.739 \\
\hline & 8 & 2.658 & 76.086 \\
\hline & 12 & 1.933 & 82.608 \\
\hline \multirow[t]{5}{*}{3} & Blank & 16.110 & \\
\hline & 2 & 5.638 & 65.000 \\
\hline & 4 & 4.833 & 70.000 \\
\hline & 8 & 4.349 & 73.000 \\
\hline & 12 & 3.222 & 80.000 \\
\hline \multirow[t]{5}{*}{4} & Blank & 18.124 & \\
\hline & 2 & 6.404 & 64.666 \\
\hline & 4 & 5.437 & 70.000 \\
\hline & 8 & 4.954 & 72.666 \\
\hline & 12 & 3.624 & 80.000 \\
\hline \multirow[t]{5}{*}{5} & Blank & 24.166 & \\
\hline & 2 & 8.699 & 64.000 \\
\hline & 4 & 7.249 & 70.000 \\
\hline & 8 & 6.863 & 71.600 \\
\hline & 12 & 4.833 & 80.000 \\
\hline \multirow[t]{5}{*}{10} & Blank & 42.291 & \\
\hline & 2 & 16.916 & 60.000 \\
\hline & 4 & 13.049 & 69.142 \\
\hline & 8 & 12.566 & 70.285 \\
\hline & 12 & 9.666 & 77.142 \\
\hline
\end{tabular}

It is also observed that, protection efficiency of red arecanut seed extract decreased with an increase in $0.5 \mathrm{M} \mathrm{HCl}$ solution temperature from $303 \mathrm{~K}$ to $323 \mathrm{~K}$. An increase of $0.5 \mathrm{M} \mathrm{HCl}$ solution temperature increases the process of hydrogen gas evolution and hence metal dissolution rate increases. The decline in the protection efficiency values may be attributed due to reduced adsorption and increased desorption process, which is due to the high thermal motion of red arecanut seed extract molecules in $0.5 \mathrm{M}$ $\mathrm{HCl}$ solution at elevated temperatures. This reflects the physical adsorption, which is associated with weak Vander Waals force existing between the red arecanut seed extract molecules and $\mathrm{Al}$ surface. The increase in the immersion time of Al metal in $0.5 \mathrm{M}$ $\mathrm{HCl}$ solution increases the metal corrosion rate, which indicates the instability of protective film for the longer contact period.
Table 2 Effect of $0.5 \mathrm{M} \mathrm{HCl}$ solution temperature on the protection efficiency (with contact time of one h)

\begin{tabular}{|c|c|c|}
\hline $\begin{array}{l}\text { Temperature } \\
(\mathrm{K})\end{array}$ & $\begin{array}{l}\text { Concentration } \\
(\mathrm{g} / \mathrm{L})\end{array}$ & $\begin{array}{l}\text { Protection efficiency } \\
\text { in percentage }(\%) \text {. }\end{array}$ \\
\hline \multirow[t]{4}{*}{303} & 2 & 66.666 \\
\hline & 4 & 72.222 \\
\hline & 8 & 77.777 \\
\hline & 12 & 83.333 \\
\hline \multirow[t]{4}{*}{308} & 2 & 65.000 \\
\hline & 4 & 70.000 \\
\hline & 8 & 75.000 \\
\hline & 12 & 80.000 \\
\hline \multirow[t]{4}{*}{313} & 2 & 63.636 \\
\hline & 4 & 68.181 \\
\hline & 8 & 72.727 \\
\hline & 12 & 77.272 \\
\hline \multirow[t]{4}{*}{318} & 2 & 60.000 \\
\hline & 4 & 64.000 \\
\hline & 8 & 68.000 \\
\hline & 12 & 72.000 \\
\hline \multirow[t]{4}{*}{323} & 2 & 59.259 \\
\hline & 4 & 62.962 \\
\hline & 8 & 66.666 \\
\hline & 12 & 70.370 \\
\hline
\end{tabular}

Activation energy $\left(\mathrm{Ea}^{*}\right)$, activation enthalpy $\left(\Delta H^{*}\right)$ and entropy $\left(\Delta S^{*}\right)$ are required to understand the Al corrosion inhibition process. For these purposes Arrhenius plots (Fig. 2, for activation energy) and transition state plots (Fig. 3, for activation enthalpy and entropy) were used.

The activation The calculated values were tabulated in Table 3. energy value in uninhibited $0.5 \mathrm{M}$ hydrochloric acid is low compared to inhibited $0.5 \mathrm{M}$ hydrochloric acid. The higher activation energy values in the presence of red arecanut seed extract molecules strongly support the results of weight loss studies and confirms the physisorption mechanism (protection efficiency decreases with an increase in $0.5 \mathrm{M} \mathrm{HCl}$ solution temperature).

The endothermic $\mathrm{Al}$ dissolution process in uninhibited $0.5 \mathrm{M}$ $\mathrm{HCl}$ and inhibited $0.5 \mathrm{M} \mathrm{HCl}$ solution was confirmed by positive activation enthalpy values. The improvement of activation entropy values is an indication of a decrease in the disorderness of the system (when shifted from reactants to activated complex).

The adsorption isotherm models are required to understand the inhibition mechanism, which give details about the molecular interaction between active electrode surfaces and red arecanut seed extract molecules. In the present study, the results of weight loss studies are best fitted to the Langmuir adsorption model (Fig. 4). 


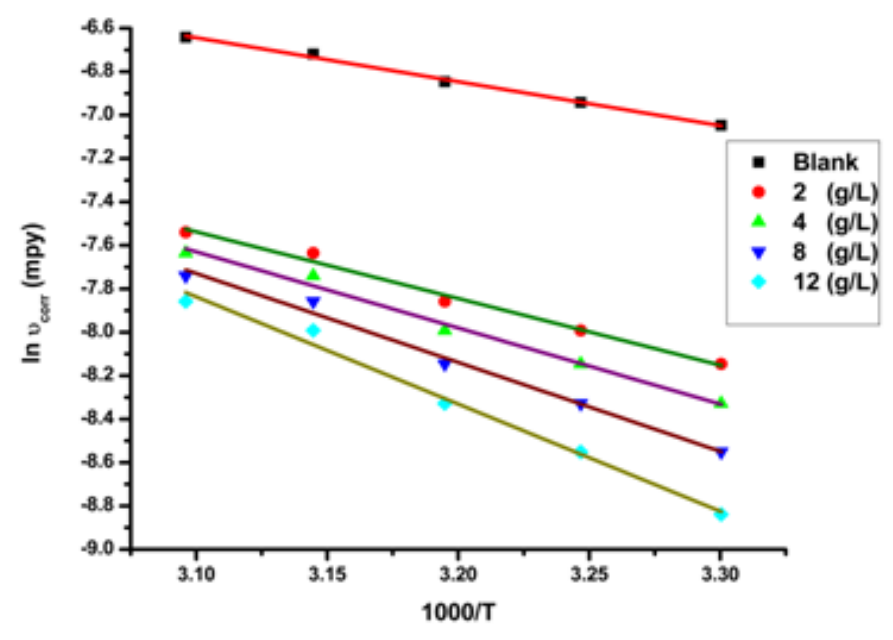

Fig. 2 Arrhenius plots (aluminum in $0.5 \mathrm{M} \mathrm{HCl}$ solution without and with red arecanut seed extract)

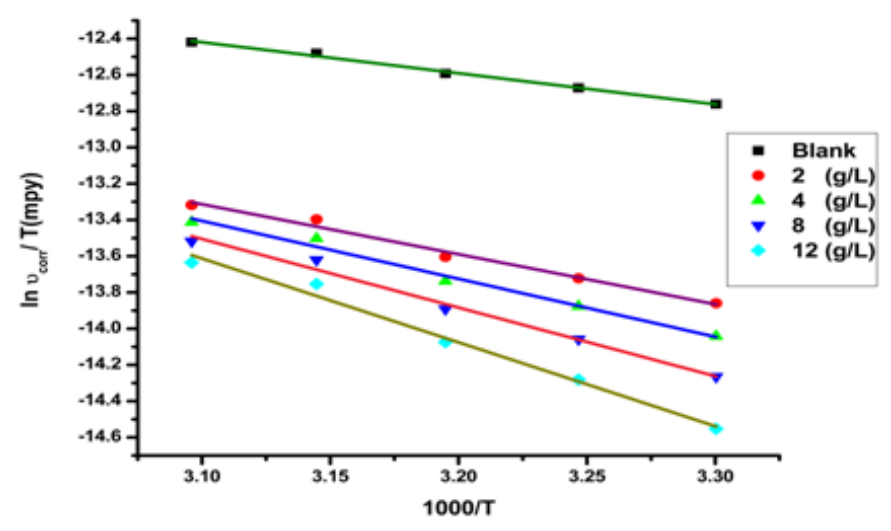

Fig. 3 Transition state plots

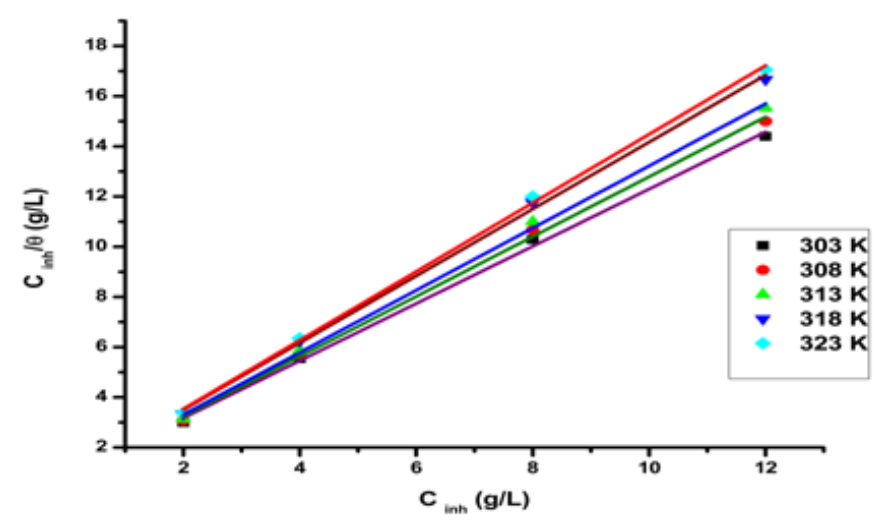

Fig. 4 Langmuir isotherm plot

Table 3 Activation parameters

\begin{tabular}{llll}
\hline $\mathrm{C}\left({ }^{g / L}\right)$ & $E \mathrm{a}^{*}\left(\mathrm{~kJ} \mathrm{~mol}^{-1}\right)$ & $\Delta H^{*}\left(\mathrm{~kJ} \mathrm{~mol}^{-1}\right)$ & $\Delta S^{*}\left(\mathrm{~J} \mathrm{~mol}^{-1} \mathrm{~K}^{-1}\right)$ \\
\hline Blank & 16.830 & 14.230 & -313.901 \\
2 & 25.534 & 22.933 & -294.352 \\
4 & 29.168 & 26.568 & -283.849 \\
8 & 34.062 & 31.462 & -269.507 \\
12 & 41.071 & 38.471 & -248.672 \\
\hline
\end{tabular}

The calculated parameters of the Langmuir adsorption model are placed in Table 4. The high equilibrium constant of the adsorption process $\left(K_{a d s}\right)$ values indicates the strong adsorption of red arecanut seed extract molecules on aluminum surface in $0.5 \mathrm{M} \mathrm{HCl}$ system. The negative standard adsorption free energy $\left(\Delta \mathrm{G}^{o}{ }_{a d s}\right)$ values indicating the adsorption process of red arecanut seed extract molecules on the surface of the aluminum in $0.5 \mathrm{M} \mathrm{HCl}$ solution are spontaneous [23]. The $\Delta \mathrm{G}^{o}{ }_{a d s}$ values obtained in the present case fall in between the range -35 to $-37 \mathrm{kj} / \mathrm{mol}$ showing that, the adsorption of red arecanut seed extract constituents on the $\mathrm{Al}$ surface in $0.5 \mathrm{M} \mathrm{HCl}$ solution is both physical and chemical adsorption.

Table 4 Thermodynamic parameters

\begin{tabular}{lll}
\hline Temperature $(\mathrm{K})$ & $K_{\text {ads }}\left(\mathrm{L} \mathrm{g}^{-1}\right)$ & $\Delta G_{\text {ads }}^{\mathrm{o}}\left(\mathrm{kJ} \mathrm{mol}^{-1}\right)$ \\
\hline 303 & 1119.106 & -35.093 \\
308 & 1160.025 & -35.764 \\
313 & 1203.224 & -36.439 \\
318 & 1198.207 & -37.010 \\
323 & 1246.416 & -37.698 \\
\hline
\end{tabular}

\subsection{Electrochemical measurements}

\subsubsection{Potentiodynamic polarization (Tafel plot studies)}

Tafel studies were carried out in order to investigate the effect of the red arecanut seed extract on cathodic and anodic reaction of aluminum. Fig. 5 represents the potentiodynamic polarization curves without and with different concentrations of red arecanut seed extract.

The corrosion current density $\left(\mathrm{i}_{\text {corr }}\right)$ values obtained from polarization curves are used to calculate the protection efficiency as by following equation,

$$
\text { Protection efficiency }=\left[1-\frac{i_{\text {corr }}}{i_{\text {corr }}}\right] \times 100
$$

where, $i_{\text {corr }}=$ the value of corrosion current density in $0.5 \mathrm{M}$ $\mathrm{HCl}$ plus red arecanut seed extract condition and $\mathrm{i}_{\text {corr }}=$ the value of corrosion current density in $0.5 \mathrm{M} \mathrm{HCl}$ condition.

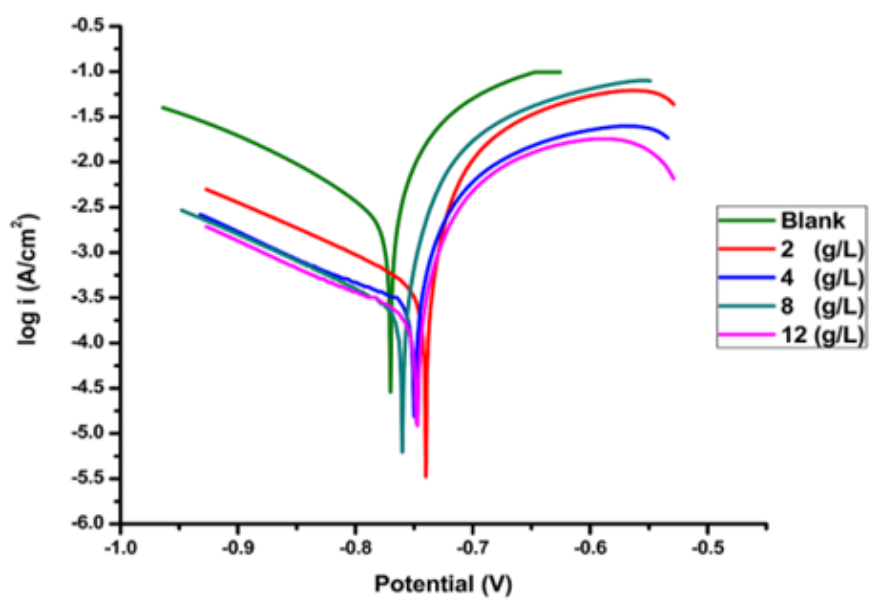

Fig. 5 Tafel plots 
The various parameters obtained from polarization curves are placed in Table 5. This indicates that, the shape of Tafel plots in unprotected system and protected system remains the same which indicates that, the addition of different amounts of red arecanut seed extract effectively hinders the corrosion current density values and did not change the aluminum corrosion inhibition mechanism process.

Table 5 Tafel plot results

\begin{tabular}{llllll}
\hline $\begin{array}{l}\text { Concentration } \\
(\mathrm{g} / \mathrm{L})\end{array}$ & $\begin{array}{l}E_{\text {corr }} \\
(\mathrm{mV})\end{array}$ & $\begin{array}{l}i_{\text {corr }} \times\left(10^{-3}\right) \\
\left(\mathrm{A} / \mathrm{cm}^{2}\right)\end{array}$ & $\begin{array}{l}\beta \mathrm{c} \\
\left(\mathrm{V} \mathrm{dec}^{-1}\right)\end{array}$ & $\begin{array}{l}\beta \mathrm{a} \\
\left(\mathrm{V} \mathrm{dec}^{-1}\right)\end{array}$ & $\begin{array}{l}\text { Protection } \\
\text { efficiency }(\%)\end{array}$ \\
\hline Blank & -770 & 8.916 & 6.679 & 6.031 & \\
2 & -740 & 1.919 & 5.852 & 6.159 & 78.476 \\
4 & -750 & 1.400 & 5.560 & 6.085 & 84.297 \\
8 & -760 & 1.340 & 5.977 & 6.976 & 84.970 \\
12 & -747 & 1.076 & 5.561 & 5.875 & 87.931 \\
\hline
\end{tabular}

The decrease in $i_{\text {corr }}$ values with improve in red arecanut seed extract concentration is due to enhanced blocked portion on the surface of the aluminum metal by red arecanut seed extract constituent's. Therefore, protection efficiency increases, whereas the corrosion rate decreases with an increase in the amount of red arecanut seed extract constituents.

The corrosion potential $\left(E_{c o r r}\right)$ and anodic $\left(\beta_{a}\right)$ and cathodic $\left(\beta_{c}\right)$ Tafel constants not shifted towards any particular side is an evidence of mixed corrosion inhibition [24, 25] properties of red arecanut seed extract molecules on aluminum metal in $0.5 \mathrm{M} \mathrm{HCl}$ solution.

\subsubsection{AC impedance spectroscopy technique}

The various parameters obtained from Nyquist plots [26-30] (Fig. 6) were presented in Table 6. The protection efficiency was determined by comparing the charge transfer resistance values without and with red arecanut seed extracts constituents as follows,

Corrosion inhibition efficiency $=\frac{\mathrm{R}_{\mathrm{ct}(\mathrm{inh})}-\mathrm{R}_{\mathrm{ct}}}{\mathrm{R}_{\mathrm{ct}(\mathrm{inh})}} \times 100$,

where, $\mathrm{R}_{\mathrm{ct}}=$ charge transfer resistance value in uninhibited $0.5 \mathrm{M} \mathrm{HCl}$ solution, and $\mathrm{R}_{\mathrm{ct}(\mathrm{inh})}=$ charge transfer resistance in inhibiting $0.5 \mathrm{M} \mathrm{HCl}$ solution.

The value of charge transfer resistance increases prominently and the value of double layer capacitance $\left(\mathrm{C}_{\mathrm{dl}}\right)$ decreases with improvement in plant extract constituents in $0.5 \mathrm{M} \mathrm{HCl}$ solution, showing that plant extract species functions through adsorption at active aluminum $-0.5 \mathrm{M} \mathrm{HCl}$ solution interface. The high charge transfer resistance values and low double layer capacitance values reflect the stumpy aluminum corrosion rate. Thus, a decline in aluminum corrosion rate and enhancement of adsorption occurs with the improve of red arecanut seed extract concentration. In the present study, the surface heterogeneity factor $(n)$ values in the range $0.695-1$, which clearly indicates that, inhibition of aluminium corrosion occurs via charge transfer phenomena. These results indicate the effective corrosion inhibition property of red arecanut seed extract for aluminum metal in $0.5 \mathrm{M}$ hydrochloric acid solution.

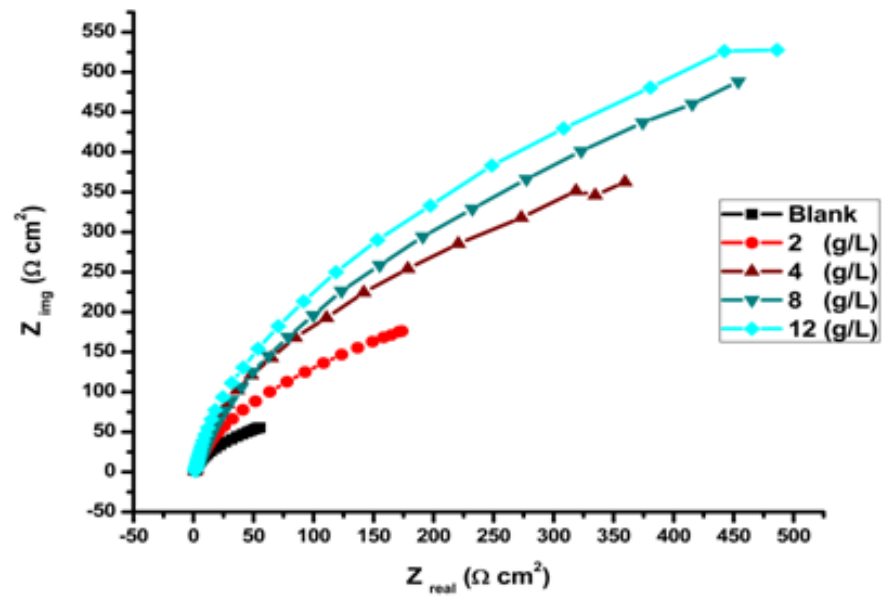

Fig. 6 Nyquist plots

Table 6 Nyquist plot parameters

\begin{tabular}{lllll}
\hline $\begin{array}{l}\text { Concentration } \\
(g / L)\end{array}$ & $n$ & $\begin{array}{l}\text { Rct } \\
\left(\Omega \mathrm{cm}^{2}\right)\end{array}$ & $\begin{array}{l}C_{d l} \\
\left(\mu F / \mathrm{cm}^{2}\right)\end{array}$ & $\begin{array}{l}\text { Protection } \\
\text { efficiency }(\%)\end{array}$ \\
\hline Blank & 1 & 55.94 & 291.355 & \\
2 & 0.914 & 187.6 & 154.609 & 70.181 \\
4 & 0.995 & 366.8 & 140.492 & 84.749 \\
8 & 0.695 & 568.1 & 109.919 & 90.153 \\
12 & 1 & 646 & 116.822 & 91.340 \\
\hline
\end{tabular}

\subsection{FT-IR spectroscopy}

The presence of functional moieties in the red arecanut seed extract was identified through FT-IR spectroscopy technique and is shown in Fig. 7 and Table 7.

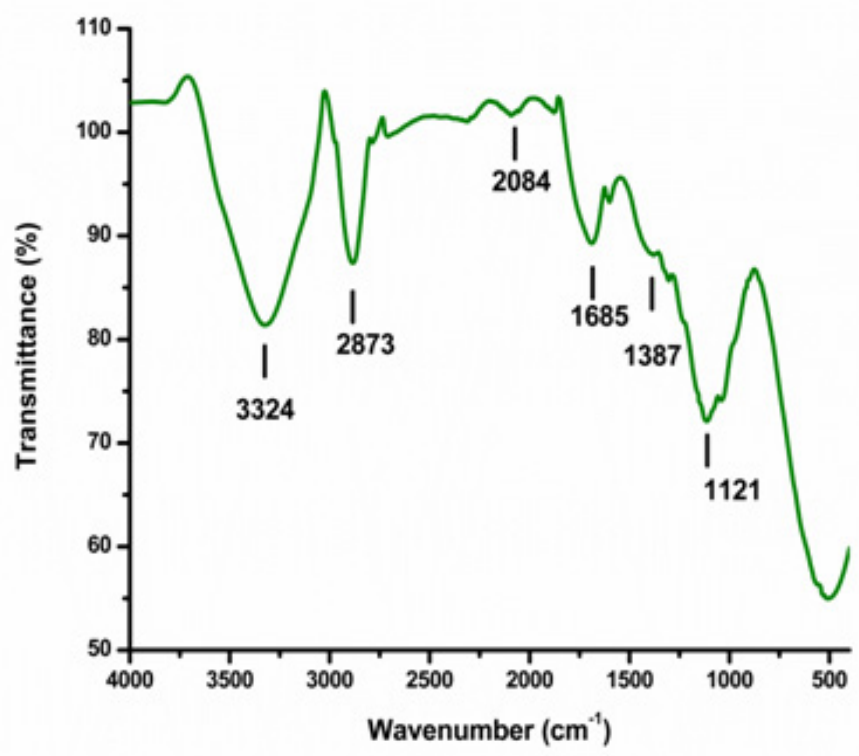

Fig. 7 IR spectrum of red arecanut seed extract 
Table 7 FT-IR results

\begin{tabular}{ll}
\hline Bands & Groups \\
\hline $3324 \mathrm{~cm}^{-1}$ & monomeric hydroxyl \\
$1685 \mathrm{~cm}^{-1}$ & carbonyl \\
$1121 \mathrm{~cm}^{-1}$ & C-O \\
$2084 \mathrm{~cm}^{-1}$ & O-C $=\mathrm{O}$ \\
$2873 \mathrm{~cm}^{-1}$ & C-H stretching \\
$1387 \mathrm{~cm}^{-1}$ & vibrations \\
\hline
\end{tabular}

\subsection{Scanning electron microscopy (SEM) technique}

The morphologies of aluminum surface submerged in the 0.5 M hydrochloric acid corrosive system without and with red arecanut seed extract constituents are shown in Fig. 8. The cracked aluminum surface in uninhibited hydrochloric acid solution indicates that, aluminum metal was badly corroded in the unprotected system by the hydrogen evolution process. But, in the case of inhibited hydrochloric acid solution, the cracked portions are changed to smooth layer which is due to coverage of red arecanut seed extract molecules on aluminum surface in $0.5 \mathrm{M} \mathrm{HCl}$ solution. Hence, a small aluminum portion is exposed to a corrosive solution.

\subsection{Atomic force microscopy (AFM) technique}

To support the SEM results, we also carried out AFM analysis and results are presented in Fig. 9 a, b and Table 8. The reduction in the roughness values (both average and root mean square roughness) in the presence of the plant extract clearly indicates the inhibitory action of green species.

Table 8 AFM results

\begin{tabular}{lll}
\hline Concentration & $\begin{array}{l}\text { Average roughness } \\
(\mathrm{Sa})\end{array}$ & $\begin{array}{l}\text { Root mean squre roughness } \\
(\mathrm{Sq})\end{array}$ \\
\hline Bare & $1036.6 \mathrm{~nm}$ & $1290.6 \mathrm{~nm}$ \\
$12(\mathrm{~g} / \mathrm{L})$ & $82.825 \mathrm{~nm}$ & $133.36 \mathrm{~nm}$ \\
\hline
\end{tabular}

\subsection{Comparison}

The maximum protection efficiency obtained from weight loss and electrochemical techniques is shown in Table 9. From this table, it is clear that, the protection efficiency obtained from the gravimetric method is slightly different from the electrochemical methods. This is because; results obtained from the weight loss studies are reported as average values, whereas as electrochemical results are reported as instantaneous values. The weight loss studies were carried out for one hour duration and electrochemical studies are carried with a stabilization period of 30 minutes. The experimental condition of weight loss technique is different from electrochemical technique. These are the main reason for the observed deviation in the protection efficiency values.

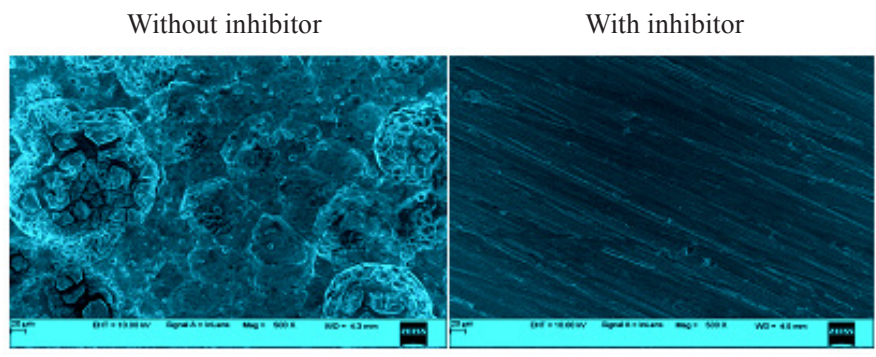

Fig. 8 SEM images (aluminum metal in $0.5 \mathrm{M} \mathrm{HCl}$ solution)
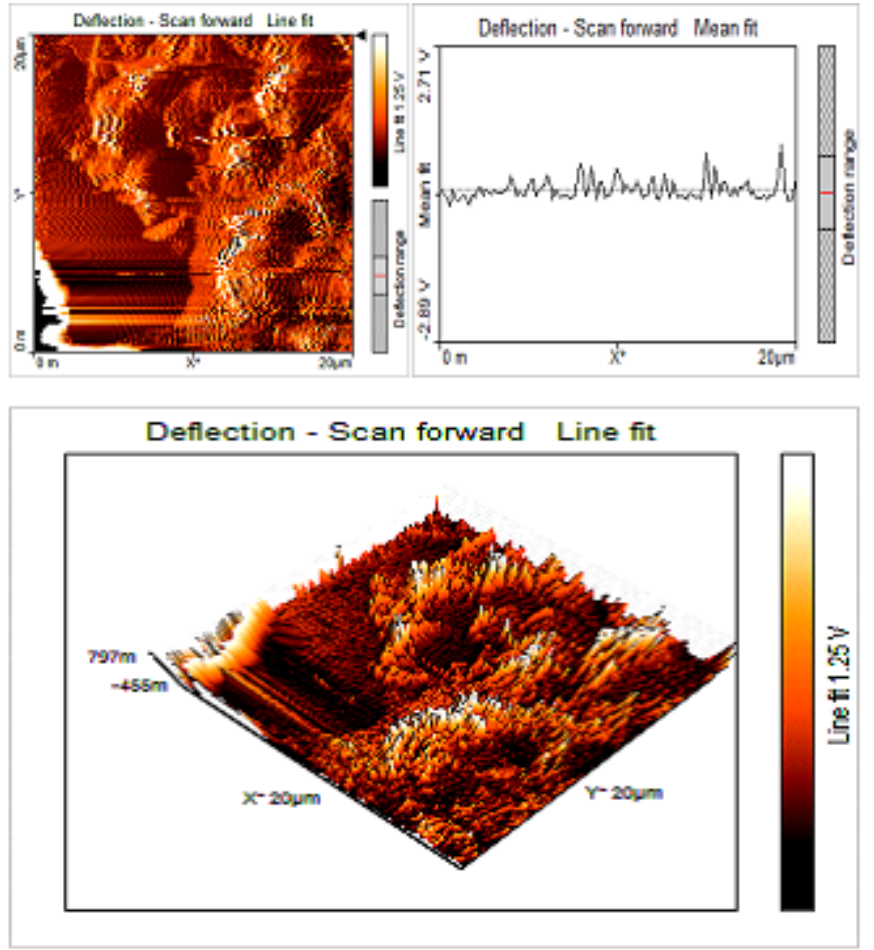

(a)
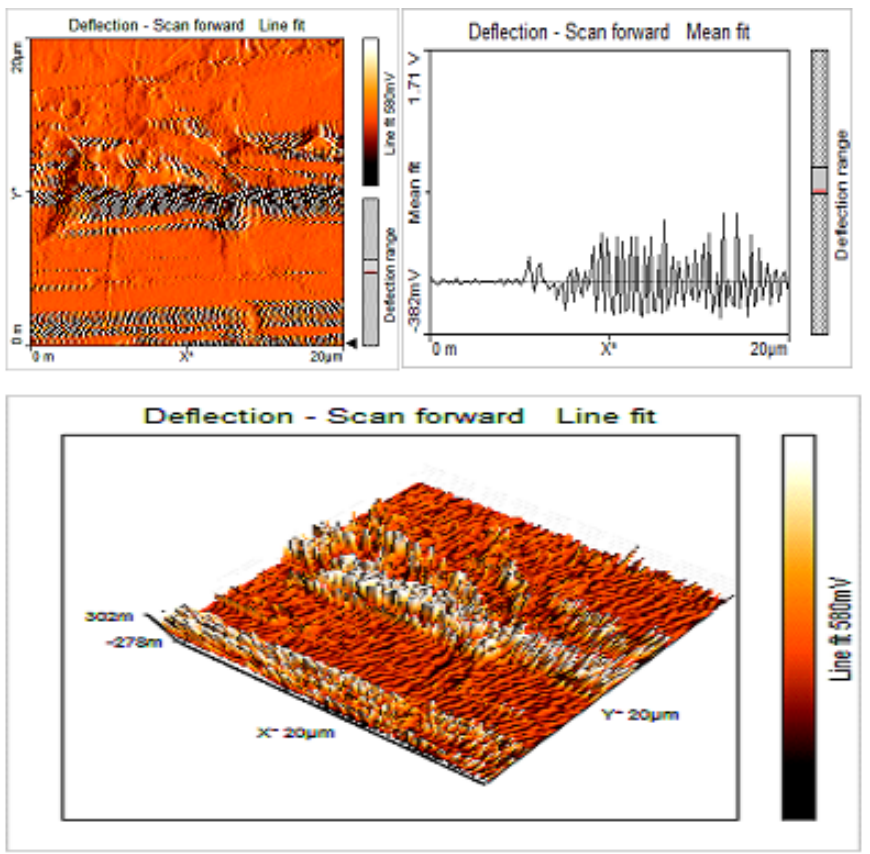

(b)

Fig. 9 (a) AFM image without inhibitor (b) AFM image with an inhibitor 
Table 9 Protection efficiency obtained from chemical and electrochemical techniques

\begin{tabular}{llll}
\hline \multirow{2}{*}{$\begin{array}{l}\text { Optimum } \\
\text { concentration } \\
(\mathrm{g} / \mathrm{L})\end{array}$} & \multicolumn{2}{l}{ Techniques (highest protection efficiency) } \\
\cline { 2 - 4 } & Weight loss & Tafel plot & $\begin{array}{l}\text { ACimpedance } \\
\text { spectroscopy }\end{array}$ \\
\hline 12 & 83.333 & 87.931 & 91.340 \\
\hline
\end{tabular}

\section{Conclusions}

The red arecanut seed extract molecules showed the potential corrosion inhibition property on the surface of aluminum in $0.5 \mathrm{M}$ hydrochloric acid environment. The efficiency of the red arecanut seed extract is increasing with increasing its amount in $0.5 \mathrm{M} \mathrm{HCl}$ solution. Slight desorption of red arecanut seed extract constituents on aluminum surface was observed with increasing solution temperature from 303 to $323 \mathrm{~K}$, which indicates the physical adsorption process. Langmuir model is well fitted for studying system. The electrochemical results (both Tafel and AC impedance spectroscopy study) confirm the adsorption of red arecanut seed extract species at aluminum$\mathrm{HCl}$ system interface. The smooth aluminum surface topography (obtained from by SEM and AFM technique) in the presence of plant product supports the inhibitory action of green inhibitor (red arecanut seed extract).

\section{Acknowledgment}

The authors thankful to Dr. B. E Kumaraswamy, Kuvempu University, for electrochemical instrument facility.

\section{References}

[1] Abdallah, M. "Antibacterial drugs as corrosion inhibitors for corrosion of aluminium in hydrochloric solution." Corrosion Science. 46, pp. 1981-1996. 2004.

https://doi.org/10.1016/j.corsci.2003.09.031

[2] Desai, M. N., Thakar, B. G., Chiaya, P. M., Gandii, M. H. "Inhibition of corrosion of aluminium-51S in hydrochloric acid solutions." Corrosion Science. 16, pp. 9-24. 1976. https://doi.org/10.1016/S0010-938X(76)80003-0

[3] Gomma, G. K., Wahdan, M. H. "Schiff bases as corrosion inhibitors for aluminium in hydrochloric acid solution." Materials Chemistry and Physics. 39, pp. 209-213. 1995. https://doi.org/10.1016/0254-0584(94)01436-K

[4] Lebrini, M., Lagrenee, M., Vezin, H., Gengembre, L., Bentiss, F. "Electrochemical and quantum chemical studies of new thiadiazole derivatives adsorption on mild steel in normal hydrochloric acid medium." Corrosion Science. 47, pp. 485-505. 2005. https://doi.org/10.1016/j.corsci.2004.06.001

[5] Moussa, M. N., Taha, F. I. M., Gouda, M. M., Singab, G. M. "The effect of some hydrazine derivatives on the corrosion of $\mathrm{Al}$ in $\mathrm{HCl}$ solution." Corrosion Science. 16, pp. 379-385. 1976. https://doi.org/10.1016/0010-938X(76)90124-4

[6] Rao, V. S., Singhal, L. K. "Corrosion behavior and passive film chemistry of 216L stainless steel in sulphuric acid. "Journal of Materials. Science. 44, pp. 2327-2333. 2009. https://doi.org/10.1007/s10853-008-2976-4
[7] Brett, C. M. "On the electrochemical behaviour of aluminium in acidic chloride solution." Corrosion Science. 33, pp. 203-210. 1992. https://doi.org/10.1016/0010-938X(92)90145-S

[8] Beck, T. R. "Size distribution of etch pits in aluminum." Electrochimica Acta. 33, pp. 1321-1327. 1988.

https://doi.org/10.1016/0013-4686(88)80121-X

[9] Fouda, A. S., Megahed, H. E., Fouad, N., Elbahrawi, N. M. "Corrosion inhibition of carbon steel in $1 \mathrm{~m}$ hydrochloric acid solution by aqueous extract of thevetia peruviana." Journal of Bio and Tribo Corrosion. 2, pp. 16. 2016. https://doi.org/10.1007/s40735-016-0046-z

[10] Brasher, D., Kingsbury, A. "The study of the passivity of metals in inhibitor solutions, using radioactive tracers. Part 1.- The action of neutral chromates on iron and steel." Transaction of Faraday Society. 54, pp. 1214-1222.1958 https://doi.org/10.1039/TF9585401214

[11] Paul, S., Koley, I. "Corrosion inhibition of carbon steel in acidic environment by papaya seed as green inhibitor." Journal of Bio and Tribo, Corrosion. 2, pp. 6. 2016. https://doi.org/10.1007/s40735-016-0035-2

[12] Xia, L., Akiyam, E., Frankel, G., McCreery, R. "Storage and release of soluble hexavalent chromium from chromate conversion coatings equilibrium aspects of Cr VI concentration." Journal of Electrochemical Society. 147 , pp. 2556-2562. 2000. https://doi.org/10.1149/1.1393568

[13] Bethencourt, M., Botana, F. J., Calvino, J. J., Marcos, M., Rodriguez, M. A. "Lanthanide compounds as environmentally-friendly corrosion inhibitors of aluminium alloys: a review." Corrosion Science. 40, pp. 1803-1819. 1998. https://doi.org/10.1016/S0010-938X(98)00077-8

[14] Mansfeld, F., Lin, S., Kim, S., Shih, H. "Pitting and surface modification of SIC/A1." Corrosion Science. 27, pp. 997-1000. 1987. https://doi.org/10.1016/0010-938X(87)90065-5

[15] Oguzie, E. E. "Corrosion inhibition of aluminium in acidic and alkaline media by Sansevieria trifasciata extract." Corrosion Science. 49, pp. 1527-1539. 2007.

https://doi.org/10.1016/j.corsci.2006.08.009

[16] El-Hosary, A., Saleh, R. M., Sharns, A. M., Dm, El. "On the electrochemical behaviour of aluminium in acidic chloride solution." Corrosion Science. 12, pp. 897-904. 1972. https://doi.org/10.1016/S0010-938X(72)80098-2

[17] Wang, C. K., Lee, W. H. "Separation, characteristics, and biological activities of phenolics in Areca fruit." Journal of Agriculture and Food Chemistry. 44, pp. 2014-2019. 1996.

https://doi.org/10.1021/jf950611o

[18] Wang, C.K., Lee, W.H., Peng, C.H. "Contents of phenolics and alkaloids in Areca catechuL. during maturation." Journal of Agriculture and Food Chemistry. 45, pp. 1185-1188. 1997. https://doi.org/10.1021/jf960547q

[19] Mathew, A. G., Govindarajan, V. S. "Polyphenolic substances of arecanut: II. Changes during maturation and ripening." Phytochemistry. 3, pp. 657-665. 1964. https://doi.org/10.1016/S0031-9422(00)82963-5

[20] Chiung-Wen, H., Chao, M.R. "Direct-acting DNA alkylating agents present in aqueous extracts of areca nut and its products." Chemical Research in Toxicology. 25, pp. 2386-2392. 2012. https://doi.org/10.1021/tx300252r

[21] Giriappa, S. "Arecanut production and marketing in india." New Delhi, ISBN 81-8588045-X. (1994)

[22] Holdsworth, D. K., Jones, R. A., Self, R. "Volatile alkaloids from Areca Catechu." Phytochemistry. 48, pp. 581-582. 1998 https://doi.org/10.1016/S0031-9422(98)00016-8 
[23] Avci, G. "Inhibitor effect of N,N'-methylenediacrylamide on corrosion behavior of mild steel in $0.5 \mathrm{M} \mathrm{HCl}$." Materials Chemistry and Physics. 112, pp. 234-238. 2008.

https://doi.org/10.1016/j.matchemphys.2008.05.036

[24] Finšgar, M. "2 Mercaptobenzimidazole as a copper corrosion inhibitor: Part I. Long-term immersion, 3D-profilometry, and electrochemistry" Corrosion Science. 72, pp. 82-89. 2013. https://doi.org/10.1016/j.corsci.2013.03.011

[25] Pavithra, M. K., Venkatesha, T. V., Punith Kumar, M. K., Tondan, H.C. "Inhibition of mild steel corrosion by Rabeprazole sulfide." Corrosion Science. 60, pp. 104-111. 2012.

https://doi.org/10.1016/j.corsci.2012.04.003

[26] Prajila, M., Joseph, A. "Controlling the rate of dissolution of mild steel in sulfuric acid through the adsorption and inhibition characteristics of (4-(4-Hydroxybenzylideneamino)-4H-1,2,4-Triazole-3,5-diyl)dimethanol (HATD)." Journal of Bio and Tribo, Corrosion. 3, pp. 10. 2017. https://doi.org/10.1007/s40735-016-0070-z

[27] Jafari, H., Akbarzade, K. "Effect of concentration and temperature on carbon steel corrosion inhibition" Journal of Bio and Tribo, Corrosion. 3, pp. 8. 2017.

https://doi.org/10.1007/s40735-016-0067-7
[28] Kuruvilla, M., Prasad, A. R., John, S., Joseph, A. "Enhanced inhibition of the corrosion of metallic copper exposed in sulphuric acid through the synergistic interaction of cysteine and alanine: electrochemical and computational studies." Journal of Bio and Tribo, Corrosion. 3, pp. 5. 2017. https://doi.org/10.1007/s40735-016-0064-x

[29] John, S., Joseph, A., Kuruvilla, M., Sajini, T. "Inhibition of mild steel corrosion using chitosan-polyvinyl alcohol nanocomposite films by sol-gel method: an environmentally riendly approach." Journal of Bio and Tribo, Corrosion. 3, pp. 3. 2017. https://doi.org/10.1007/s40735-016-0062-z

[30] Mohan, R., Anupama, K.K., Joseph, A. "Effect of methyl, ethyl, and propyl substitution on benzimidazole for the protection of copper metal in nitric acid: theoretical and electrochemical screening studies." Journal of Bio and Tribo, Corrosion. 3, pp. 2. 2017.

https://doi.org/10.1007/s40735-016-0061-0 